UNITED STATES DEPARTMENT OF THE INTERIOR GEOLOGICAL SURVEY

\title{
LANDSAT LINEAR FEATURE DATA OF THE \\ GALLUP-GRANTS URANIUM DISTRICT, NEW MEXICO \\ by
}

Robert S. Zech and

Daniel H. Knepper, Jr.

Open-File Report 79-1507

1979 


\section{Introduction}

The purpose of this report is to present linear feature data mapped from computer-enhanced Landsat images of the Gallup-Grants uranium district, northwest New Mexico (fig. 1), and to demonstrate how the linear feature data are acquired and analyzed for length, preferred orientation, and spatial distribution. characteristics. The results of the analyses could then be be integrated with other geological, geophysical, and geochemical data to evaluate the geologic significance of the linear features and

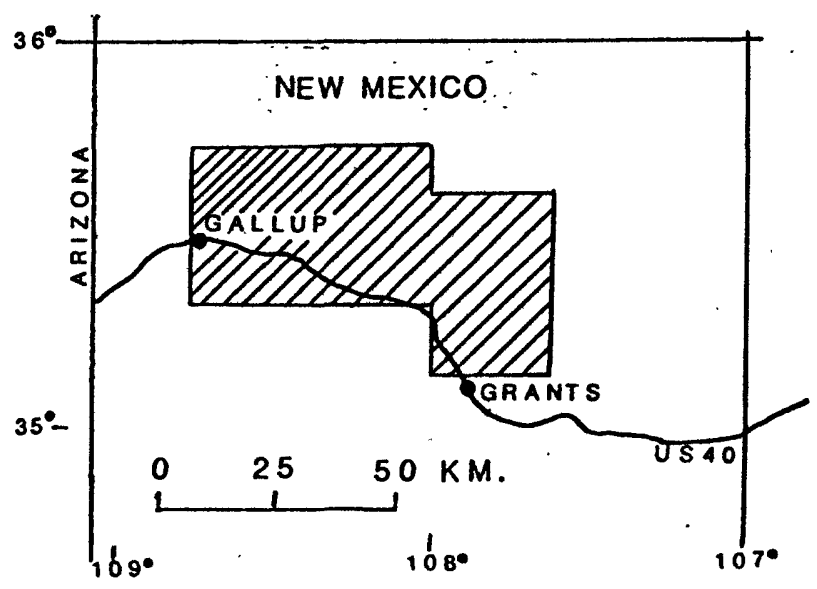

Figure 1. Index map showing location of study area. their regional patterns.

\section{Landsat Data}

The two sets of Landsat images, that were used in the linear feature mapping, were prepared from the digital data by the U.S. Geological Survey EROS Data Center, Sioux Falls, South Dakota. Digital image-enhancement techniques were applied to the primary image data (landsat scene 5181-16512) to correct for six-line banding, geometric and radiometric distortion, and line dropouts. Contrast on the image was enhanced at the EROS Data Center by stretching and edge enhancement techniques as described in Sabins (1978). Black and white images of each of the four multispectral scanner system (MSS) bands and a false color infrared composite prepared from MSS bands 4, 5, and 7, all at a scale of 1:1,000,000, were examined for linear features. In addition, interpretation of a 1:250,000-scale print of a false color infrared 
composite of scene 1425-17193, scanned in September 1973 shortly after a period of rainfall, was extremely useful for recognizing subtle linear features; these features are expressed primarily by vegetation patterns not observed on the primary set of images.

\section{Linear Features Mapping}

Linear features were first identified and mapped on an overlay on the $1: 1,000,000$-scale images, then transferred to a $1: 250,000$ topographic map. Most of the linear features are expressed as topographic break in slope or as elongated topographic lows. A few, however, are expressed only by a change of image tone. These tonal features, prominent in the northwest and central parts of the study area were either most prominently expressed or only seen on the false color infrared composite of scene 1425-17193, and may be due to subtle variations in vegetation density enhanced by the period of rainfall shortly before the image was scanned.

Most of the mapped linear features have a single type of surface expression. A few of the linear features, however, are formed by an alinement of linear elements with differing types of image and surface expression. In general, the majority of linear features are topographically expressed and most easily seen on the false color infrared composites and the black and white image of the band 5 data.

The completed map of linear features was digitized for computer analysis. Only the end points of the individual linear features needed to be digitized to accurately reproduce the lines. Figure 2 is a computer-generated plot of the linear features map. Computer plotted linear features typically are straighter than linear features mapped on images. 


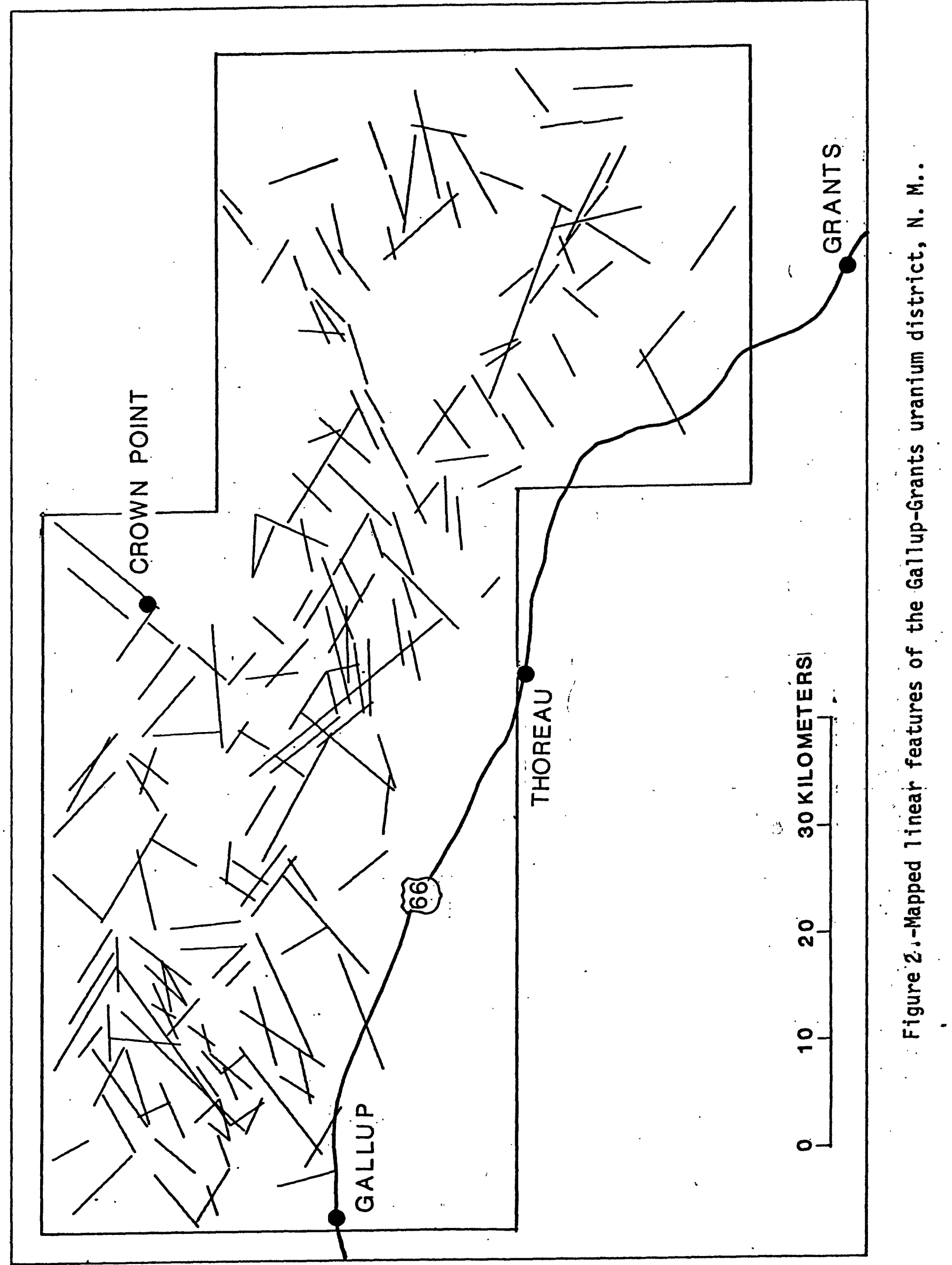


Characteristics of Linear Feature Data Set

With data sets containing a relatively small number of linear features, it is usually possible to evaluate important trends and patterns by visual examination of the map. As the data sets become larger, they also become more complex, and visual evaluation alone is no longer sufficient. Sawatzky and Raines (1979) describe some analytical techniques for characterizing complex linear feature data sets in terms of lengths and orientation. These techniques have found application in a variety of geologic terrains and are used in this report (Raines, 1978; Raines and others, 1978; Knepper, 1978; 1979). A brief description of these analysis is given below. Length Frequency Analys is

The length frequency analys is computer program plots a histogram of the length of linear features as a function of their frequency of occurrence. (Appendix C). In addition, the following were also calculated in length frequency analysis.

$\begin{array}{lc}\text { Longest linear feature } & 17.2 \mathrm{~km} \\ \text { Shortest linear features } & 2.1 \mathrm{~km} \\ \text { Mean length } & 5.25 \mathrm{~km} \\ \text { Mode length } & 4.5 \mathrm{~km} \\ \text { Standard deviation } & 2.5 \mathrm{~km}\end{array}$

The abrupt minimum length cut off observed in the length frequency histogram is typical of linear feature data mapped from Landsat images (D. $H$. Knepper, unpublished data). The cutoff is a function of the resolution of the Landsat system (79 meter-square ground resolution), map scale, and the image quality. The number of mapped linear features with lengths greater than the modal length decreases exponentially, producing a histogram with an approximately log normal distribution. 
Strike Frequency Analys is

The strike frequency analysis used in this study determines the frequency of occurrence of linear features in each of the 180 one-degree azimuthal classes. The significance value of a given frequency of occurrence is based on the probability of that frequency occurring in a given data set with a uniform population of directions (Raines, 1978). Low significance values occur when the frequency is near the mean frequency. Higher significance values occur as the frequency of occurrence deviates from the mean value.

In the length weighted strike-frequency analysis, each linear feature is weighted proportional to its length. This technique is used to emphasize the potential importance of the longer features and to enhance trends containing these longer linear elements. Computer printouts of the results of the unweighted and length weighted strike frequency analyses can be found in Appendices $B$ and $C$. The analyses are replotted in figures 3 and 4 to better display the relationship between strike frequency and significance value and to show the degree of preferential orientation in the linear feature data set. In the unweighted analyses (fig. 3), a 90.6 significance value (10 linear features in a one-degree interval) was chosen as indicating a strong preferential orientation. In the length weighted analyses (fig. 4), preferred orientation is similarly indicated when the curve reaches a 94.0 percent significance value.

In the Gallup-Grants data, the unweighted strike frequency analys is shows five narow trend intervals extending above the 90.6 significance value (fig. 3). In the length weighted analys is many peaks are in the significant field (fig. 4). These results are presented in table 1. 


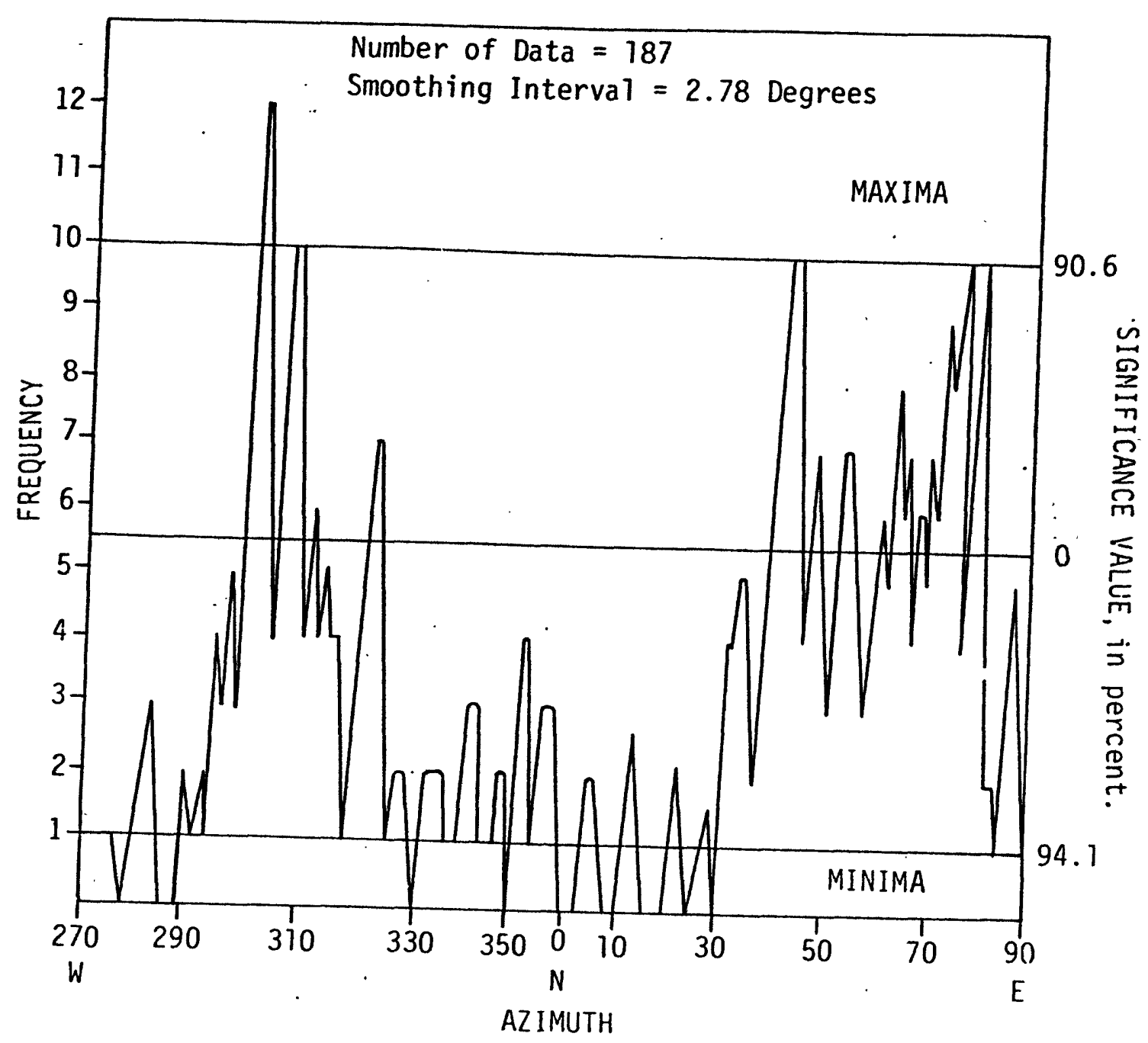

Figure 3.--Unweighted strike-frequency histogram of linear features GallupGrants area. 


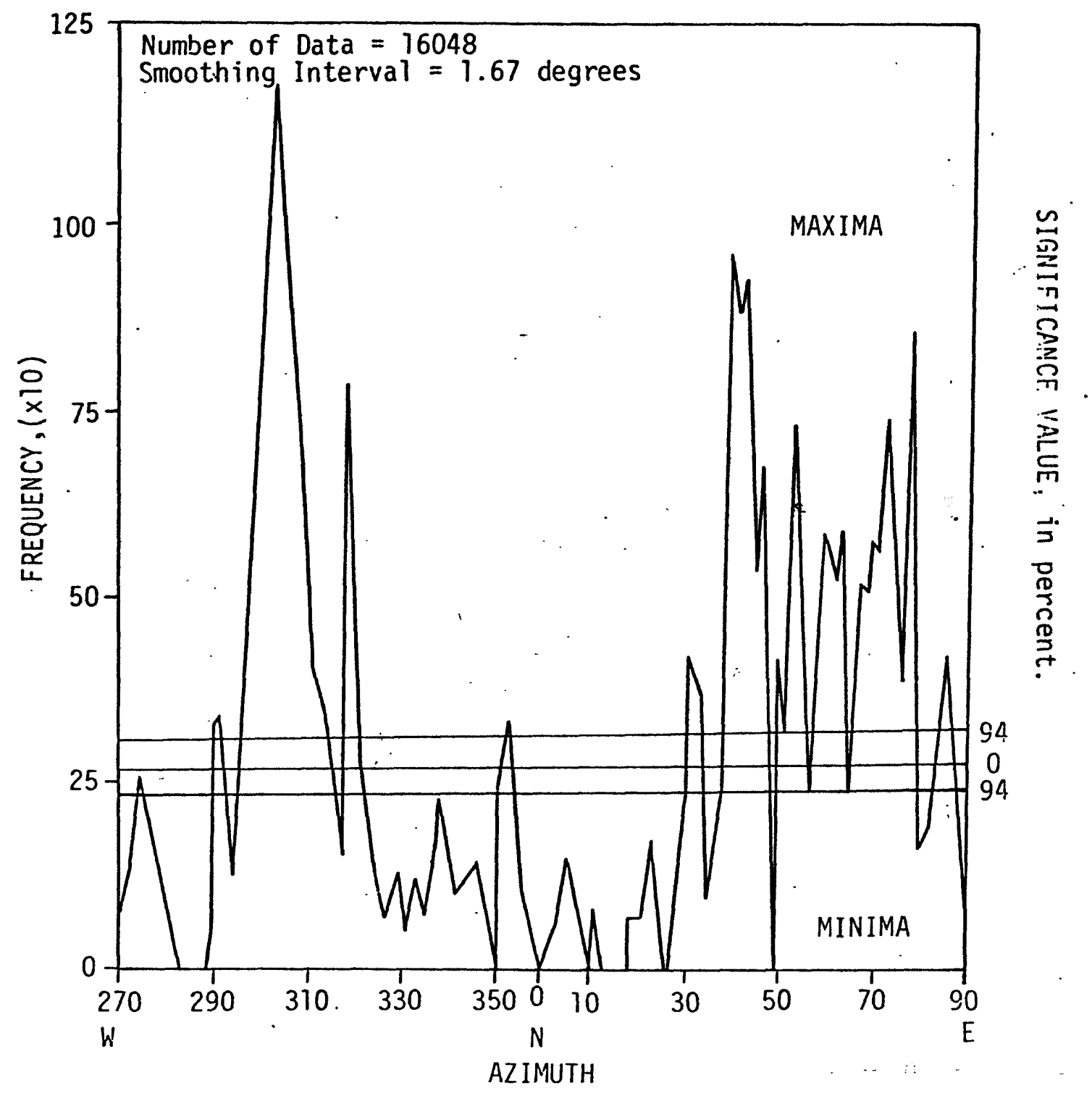

Figure 4 .--Length weighted strike-frequency histogram of the Gallup-Grants area. 
Table 1.--Azimuthal trends, of the significant maxima, from the unweighted and length weighted strike-frequency analys is in degrees for the

Gallup-Grants Uranium District

\begin{tabular}{|c|c|c|c|}
\hline \multicolumn{2}{|c|}{ Unweighted } & \multicolumn{2}{|c|}{ Length weighted } \\
\hline Maxima & ar width & Maxima & Angular width \\
\hline $301-302$ & 2 & 290 & 1 \\
\hline $306-307$ & 2 & 292 & 1 \\
\hline $39-41$ & 3 & 296 & 1 \\
\hline 73 & 1 & $298-315$ & 18 \\
\hline \multirow[t]{8}{*}{77} & 1 & $320-322$ & 3 \\
\hline & & 353 & 1 \\
\hline & & $32-34$ & 3 \\
\hline & & $39-41$ & 3 \\
\hline & & $43-46$ & 4 \\
\hline & & $49-56$ & 8 \\
\hline & & $59-73$ & 15 \\
\hline & & $86-88$ & 3 \\
\hline
\end{tabular}

It is often useful to group the many narrow trend intervals into several broader trend intervals that are characteristic of the region. One method for selecting the maxima points and end points of each of the broader trend intervals was presented by Knepper (1979) and is outlined below.

(1) Significant maxima were chosen by picking only those intervals common to both the length weighted and the unweighted strike frequency analyses.

(2). If a maximum interval is directly adjacent to a minimum, the 1-degree maximum azimuthal trend closest to the adjacent minimum is selected as the end point.

(3) If the maximum is separated from the nearest minimum by a field of nonsignificant 1-degree trends, the 1-degree azimuthal trend one-half the 
angular distance between the minimum and maximum is chosen as end point. If the difference in azimuth is an odd number of degrees, the extra 1-degree of azimuth is included in the maximum interval.

Applying this method of trend interval selection to the Gallup-Grants linear feature data resulted in the definition of three relatively broad trend intervals of $34^{\circ}$ to $44^{\circ}, 60^{\circ}$ to $80^{\circ}$, and $298^{\circ}$ to $312^{\circ}$.

Linear features of any specified trend interval may be easily viewed by means of computer graphics. The computer graphics plot of the desired trend interval may then be visually analyzed for cluster, alinements, or other linear feature distribution patterns which may be suggestive of possible geologic or tectonic conditions. Figures 5 through 7 are computer plots of the linear features contained in broad selected trend intervals in the GallupGrants study area.

9 


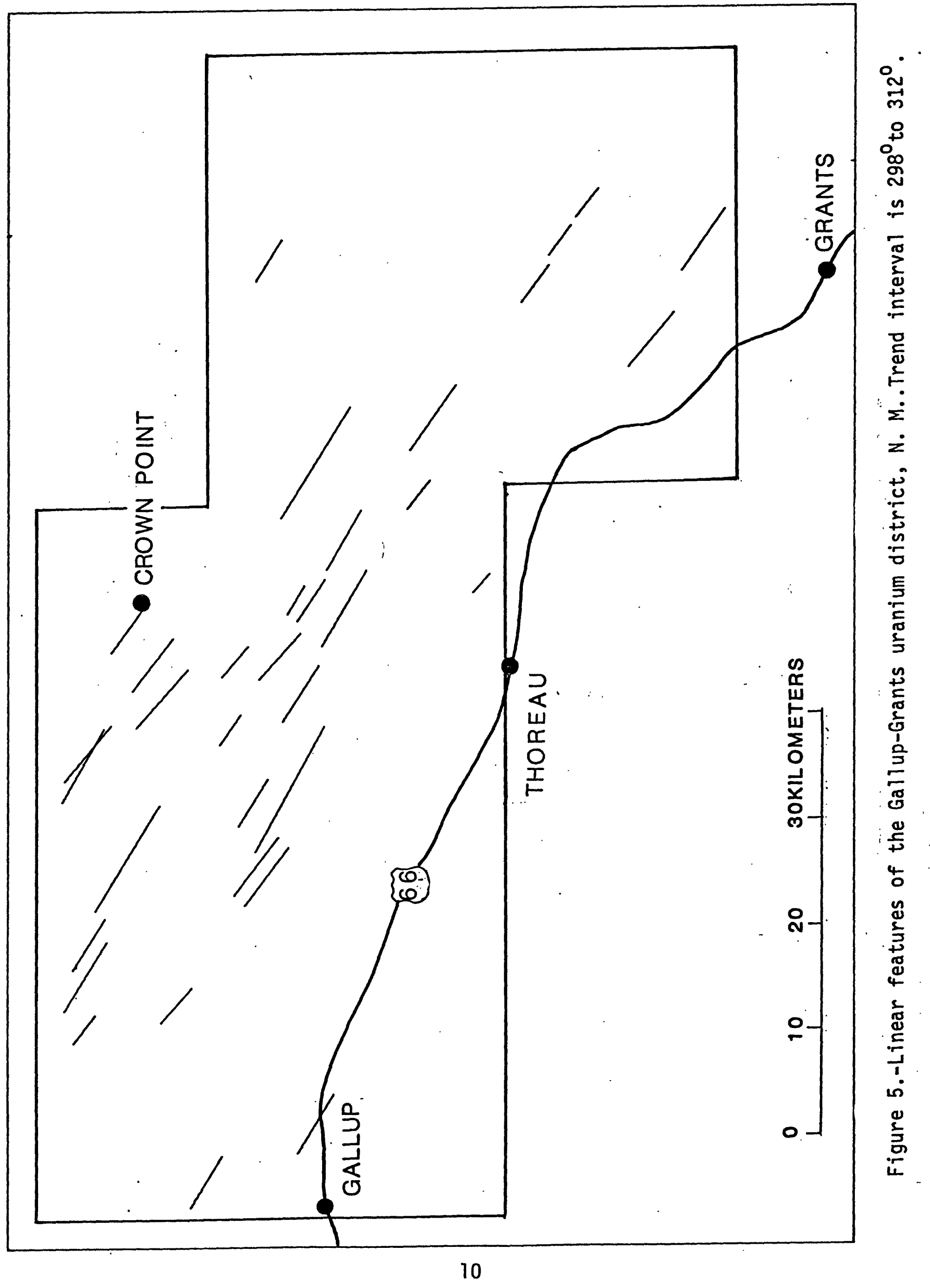




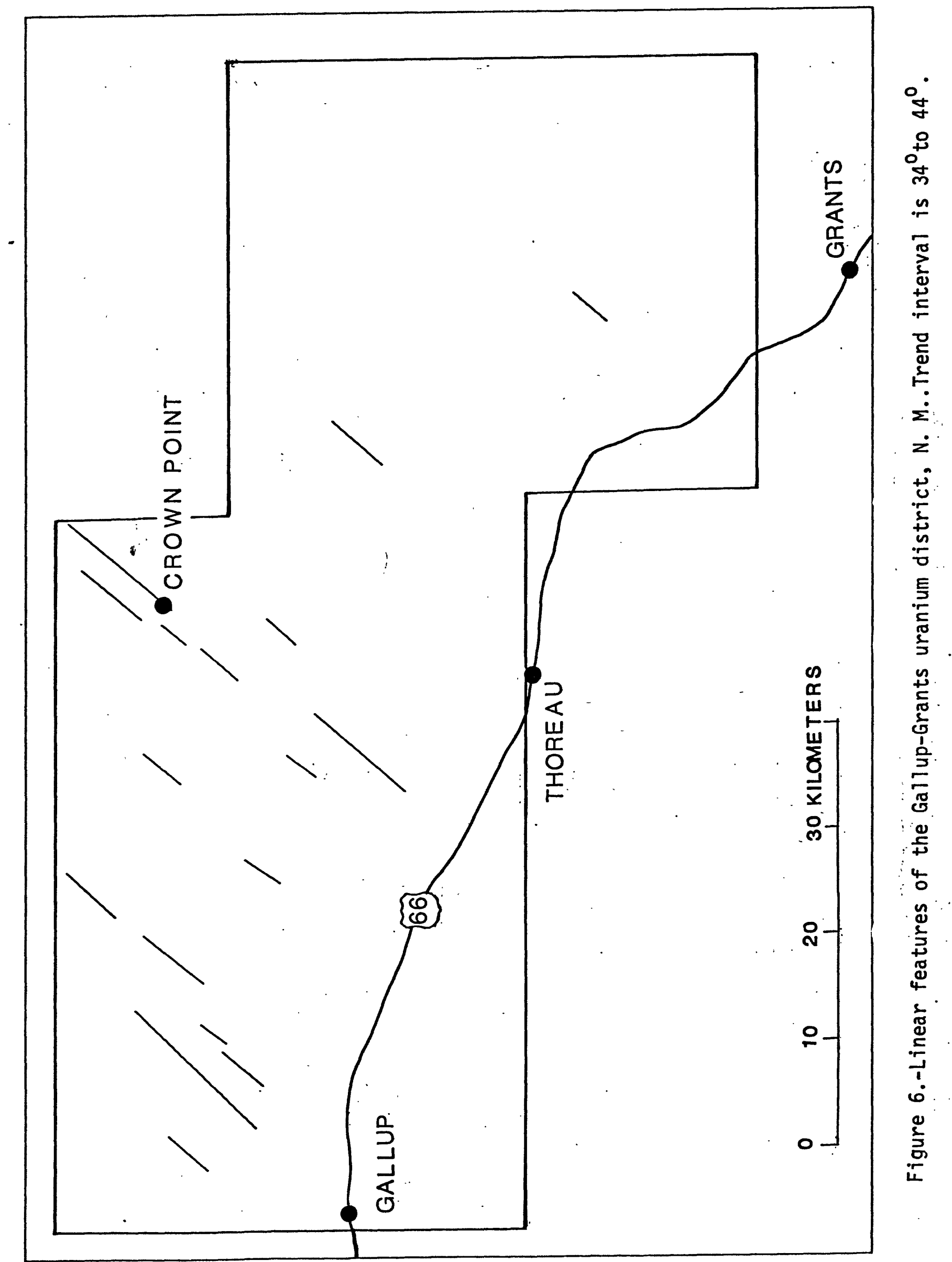




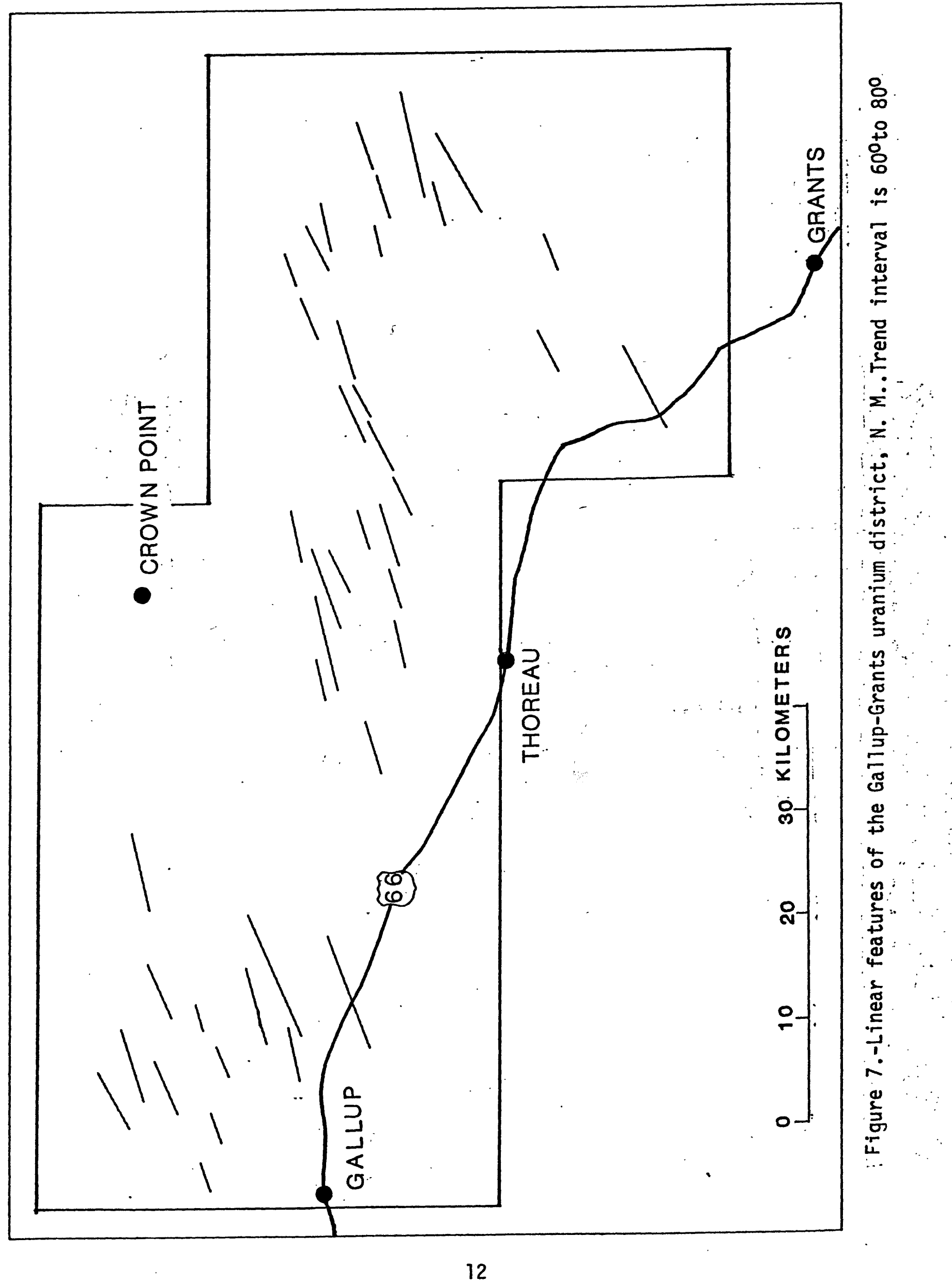




\section{References cited}

Knepper, D. H., Jr., 1978, Analysis of linear features, Rio Grande rift zone, central New Mexico [abs.], in Conference Proceedings, 1978 International Symposium on the Rio Grande Rift, Santa Fe, New Mexico: Los Alamos Scient ific Laboratory report LA-7487-C, p. 48-49. 1979, Linear feature data derived from Landsat images of southeastern Missouri: U.S. Geological Survey Open-File Report 79-992, 44 p. Raines, G. L., 1978, Porphyry copper exploration model for northern Sonora, Mexico: U.S. Geological Survey Journal of Research, v. 6, no. 1, p. 51-58.

Raines, G. L., Offield, T. W., and Santos, E.S., 1978, Remote sensing and subsurface definition of facies and structure related to uranium deposits, Powder River Basin, Wyoming: Economic Geology, v. 73, p. 1706-1723.

Sabins, F. F., Jr., 1978, Remote Sensing Principles and Interpretation: San Francisco, Calif., W. H. Freeman and Company, p.. 65-116. Sawatzky, D. L., and Raines, G. L., 1979, Geologic uses of linear feature maps from small-scale imagery: Proceedings of Third International Conference on Basement Tectonics, in press. 
Appendix A

Computer Printout

Computer Printout Length Frequency Analys is 
$02 / 07 / 790959$

START LINE 1; START PIXEL 1; NO. LINES 18; NO. PIXEL 10 LINE SKIP $0:$ PIXEL SKIP 0

MIN GRAY LEVEL 0: MAX GRAY LEVEL 300: MEAN GRAY LEVEL 84.1 MODE: GRAY LEVEL 72 UCCURS 6. TIMES

TUTAL PIXELS TESTED 180.

I.OW PIXELS OI HIGH PIXELS
PIXELS USED IN HISTOGRAM

VARIANCE 1639.026 STANDARD UEVIATION 40.485

FREQUENCY HISIOGRAM-NURMALIZEO TO 50

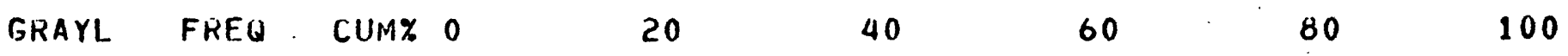

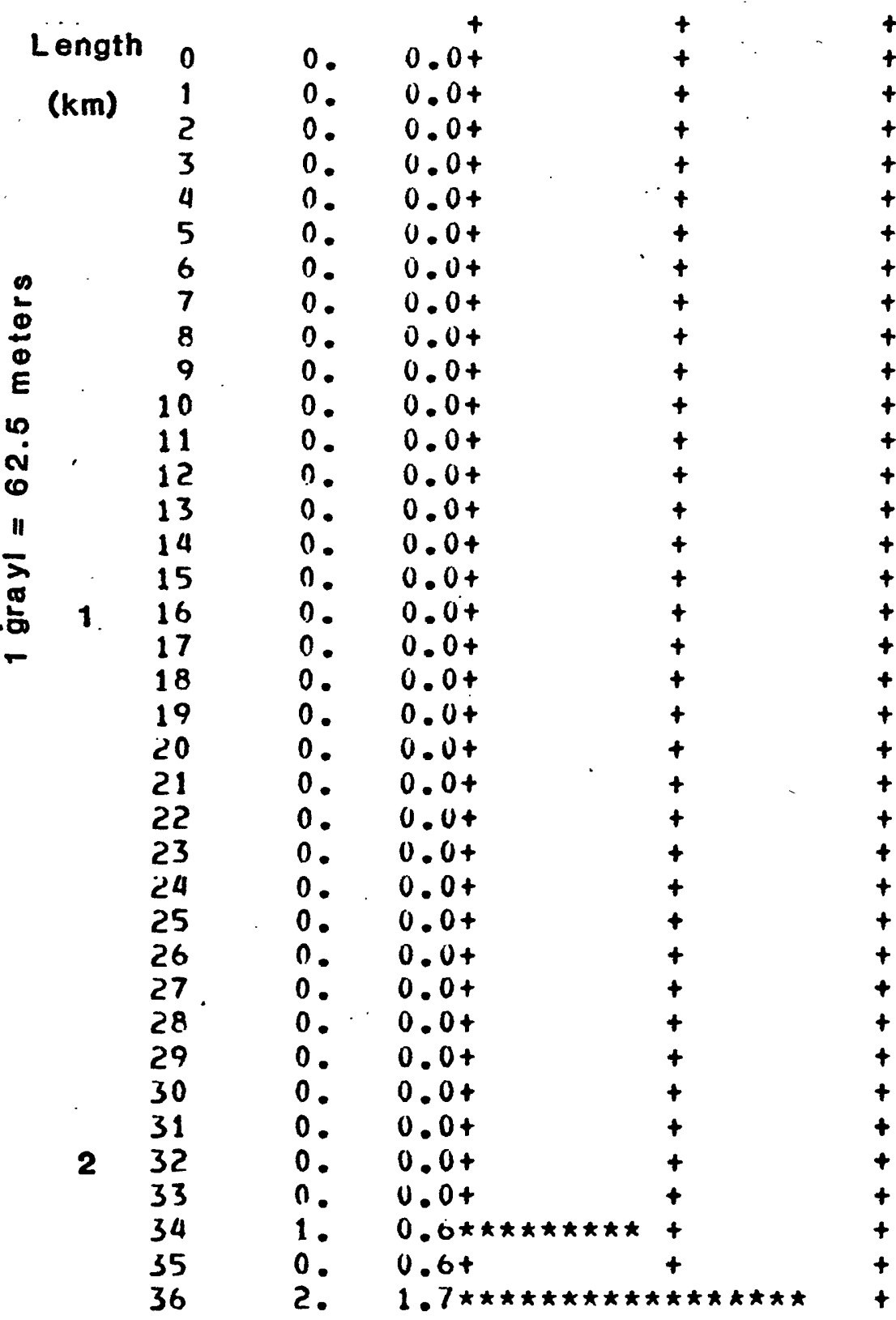




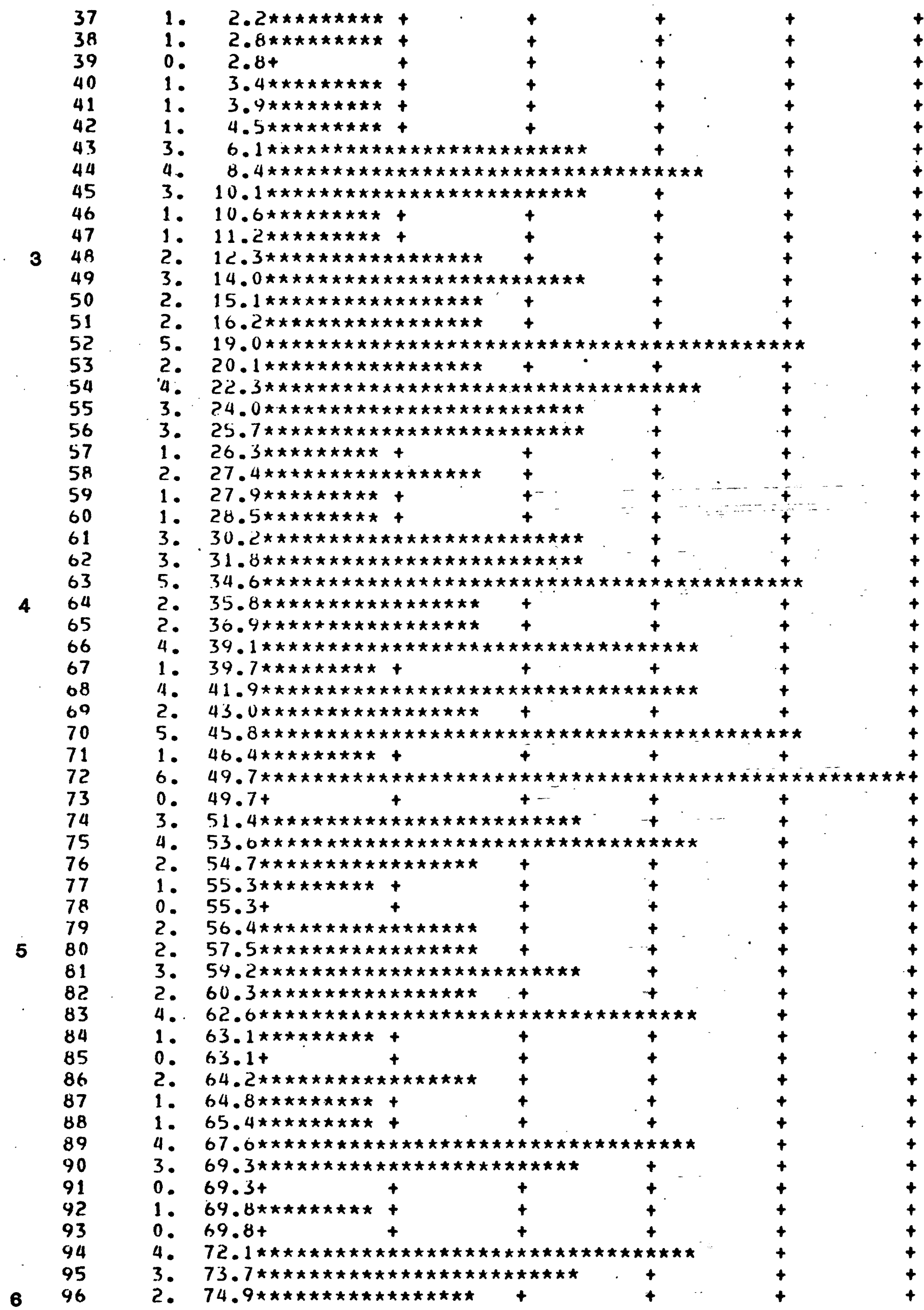




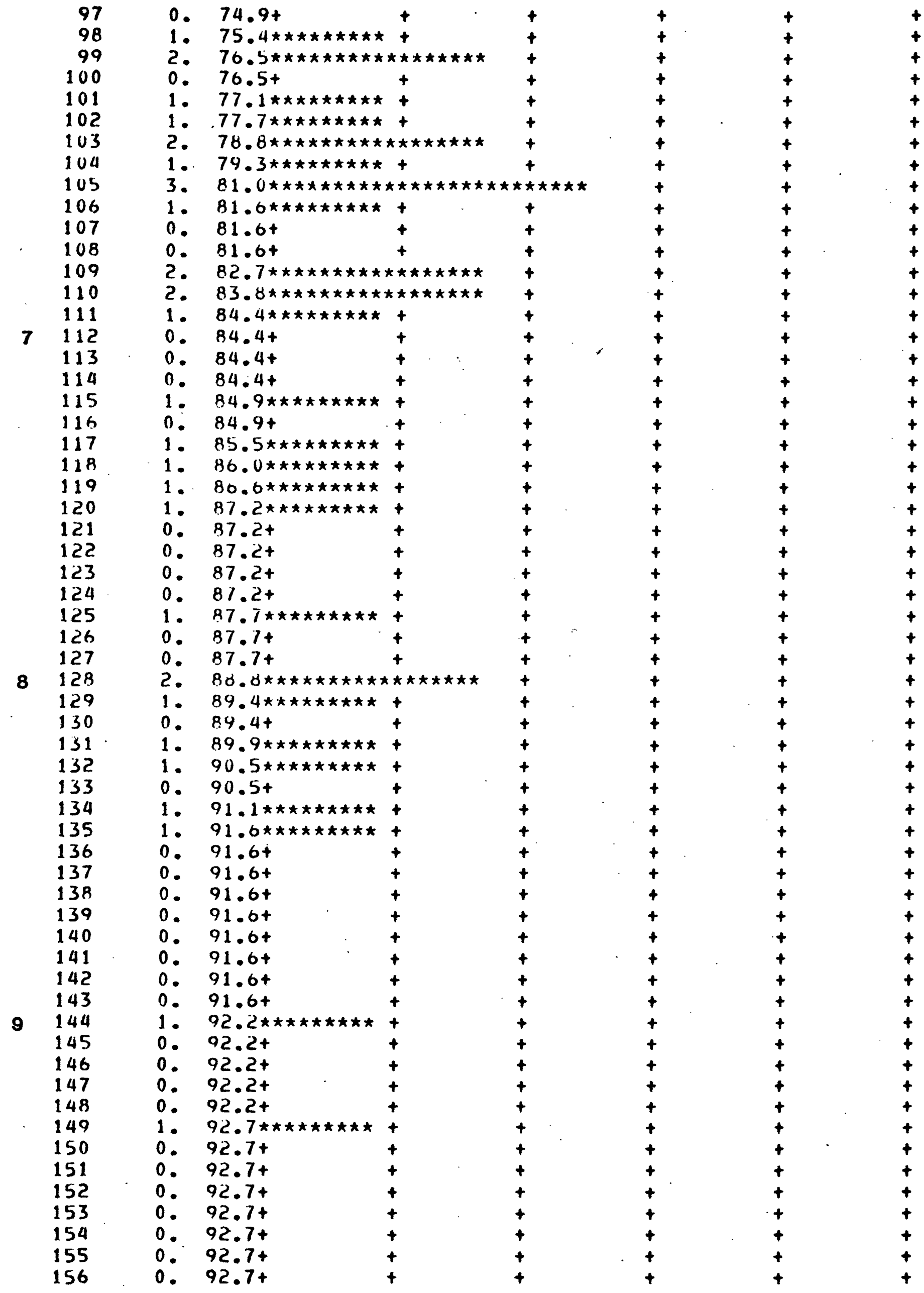




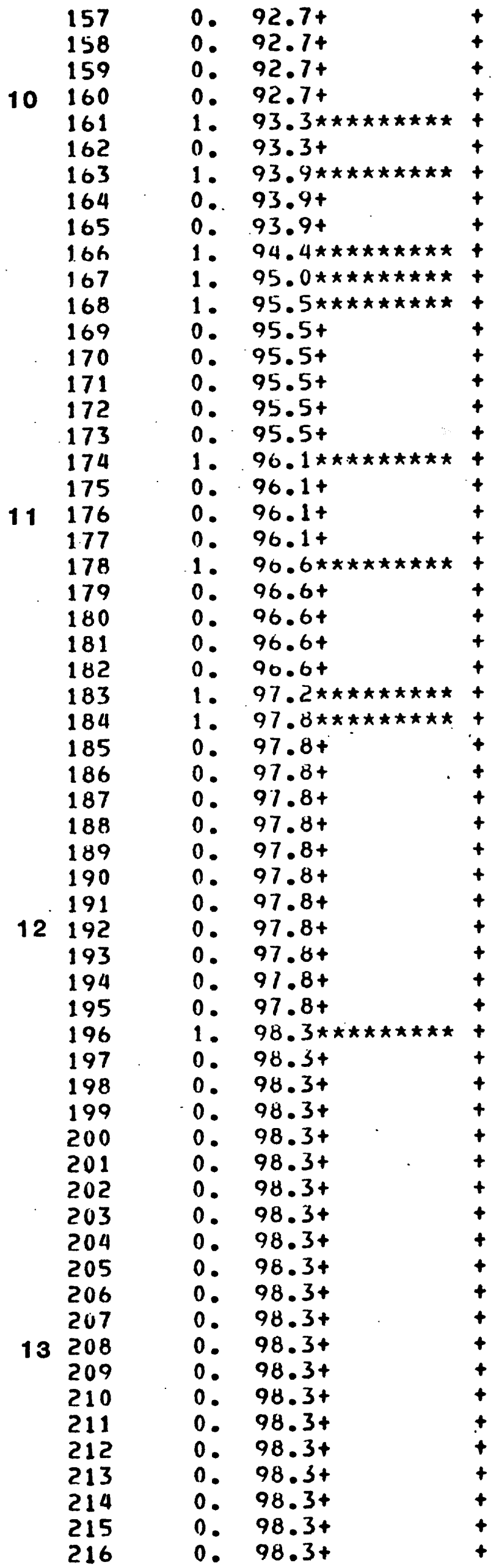




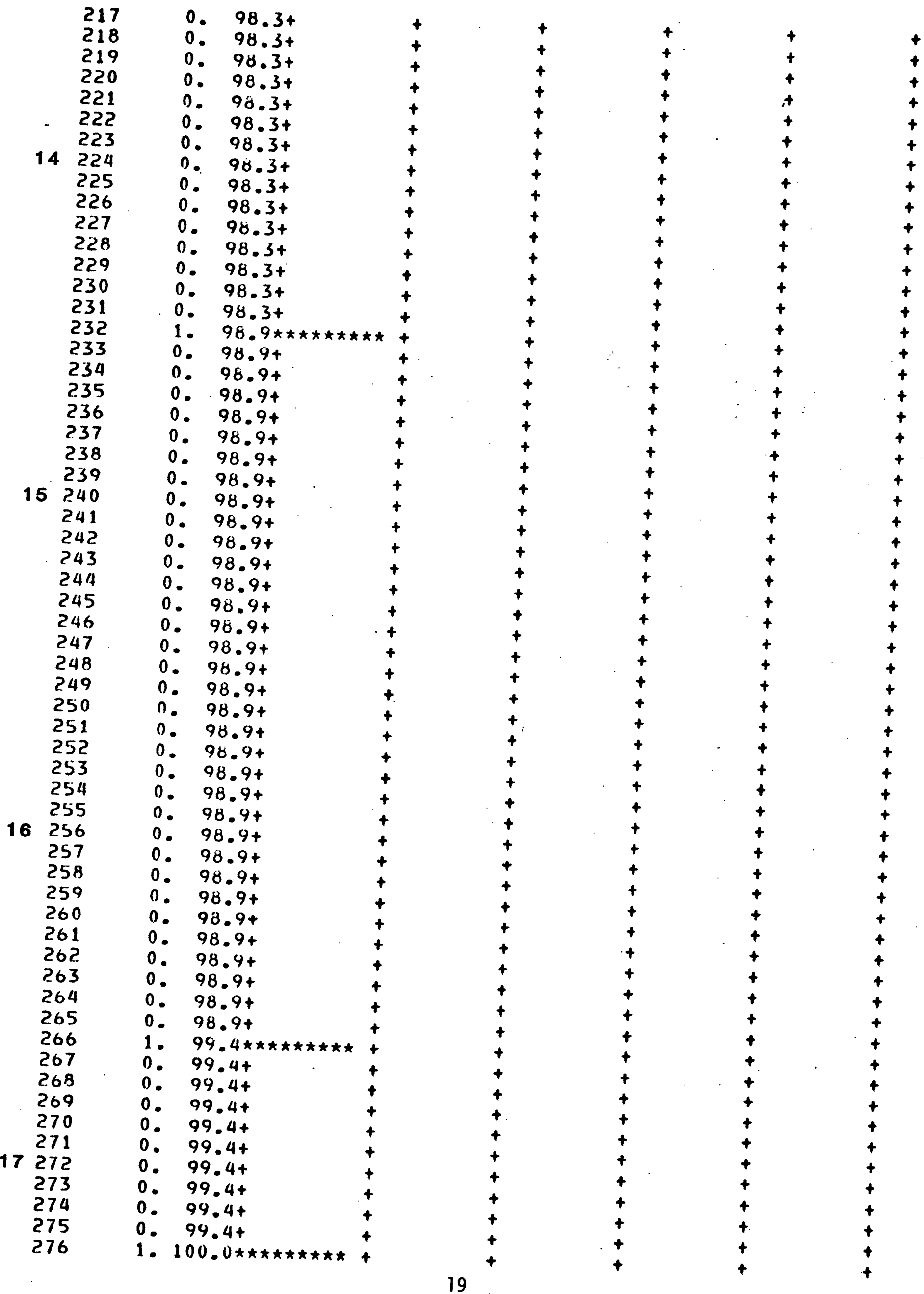




\author{
Appendix B \\ Computer Printout \\ Unweighted Strike-Frequency Analys is
}




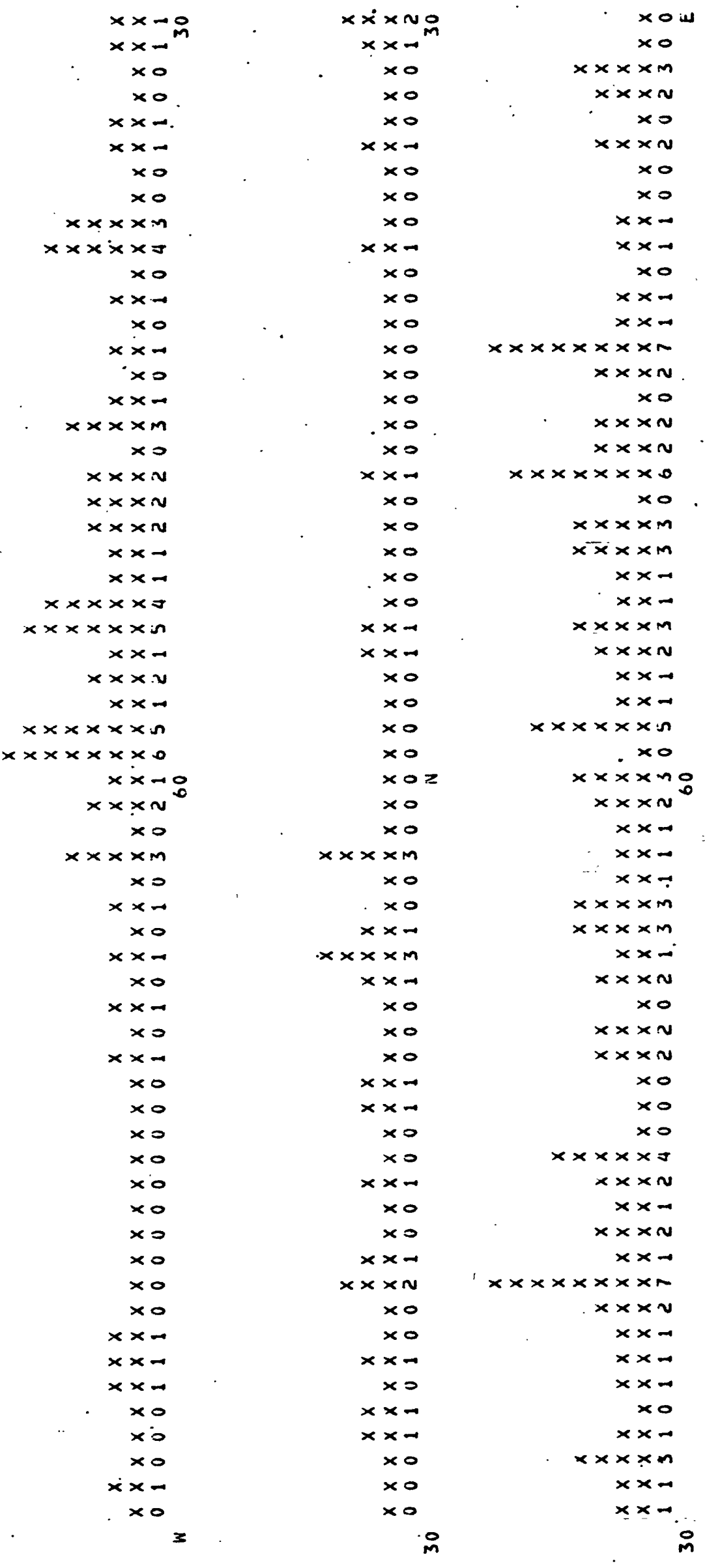

21. 

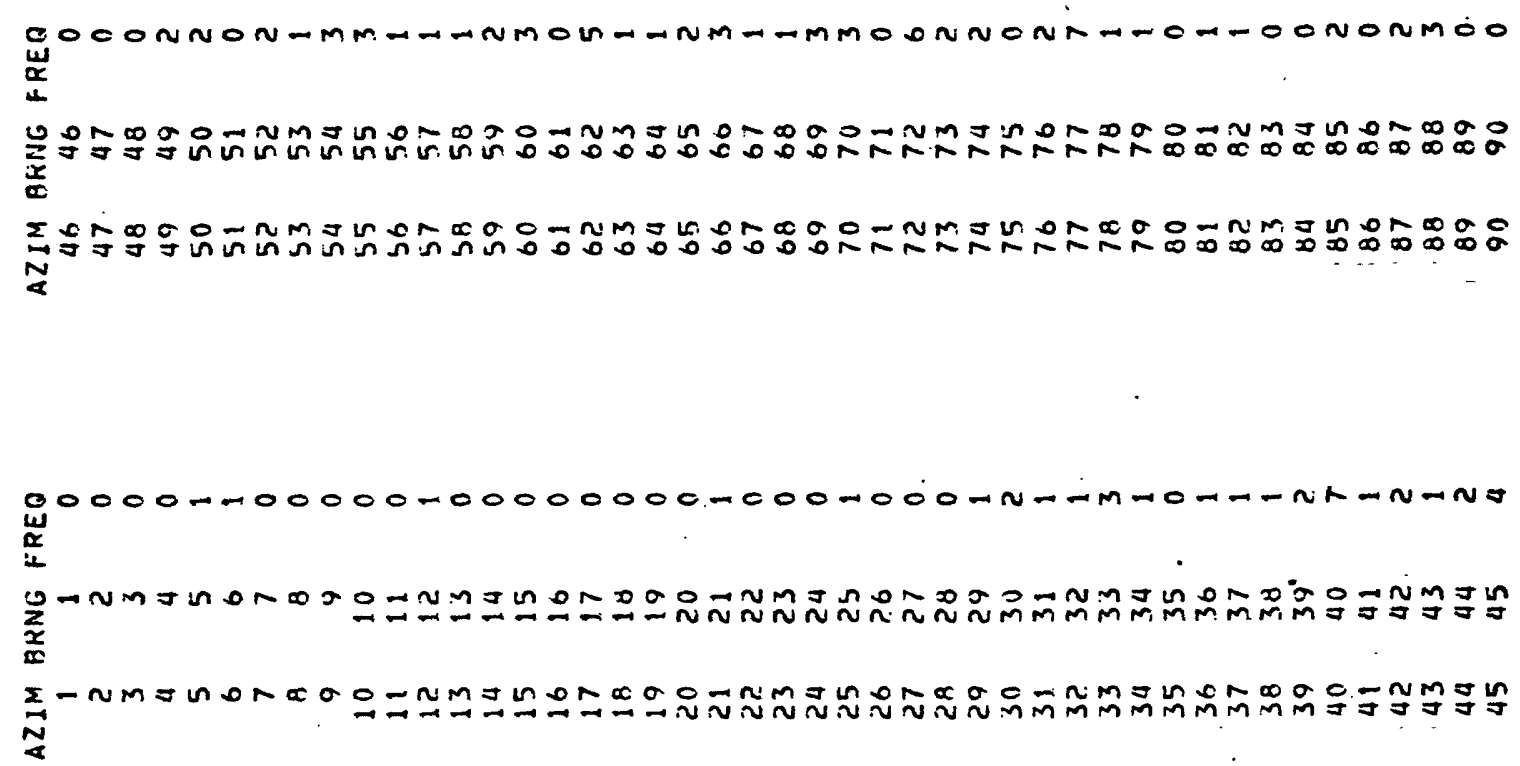

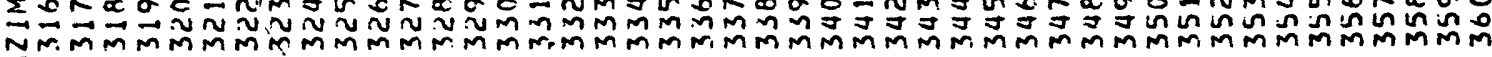

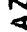

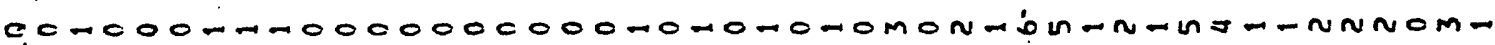
崫

多可

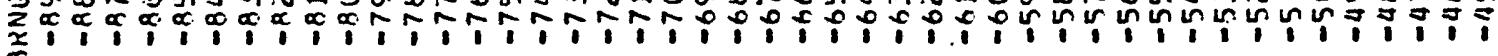

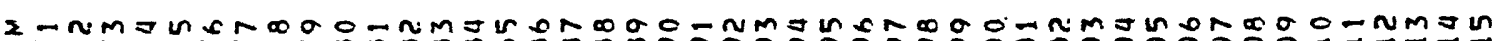

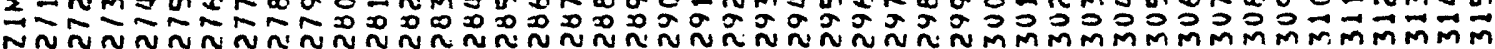

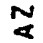




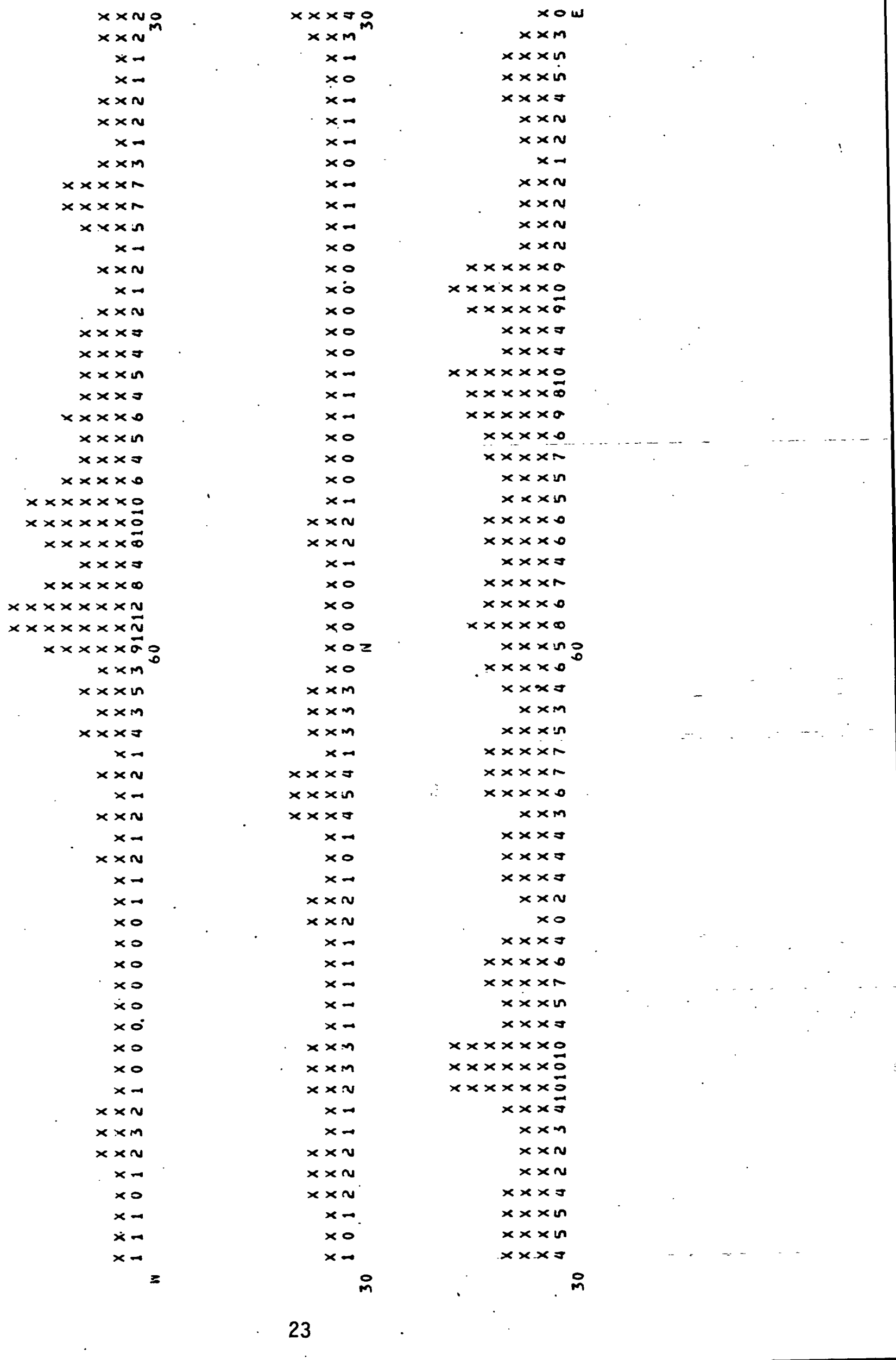


co $\frac{1}{4}$

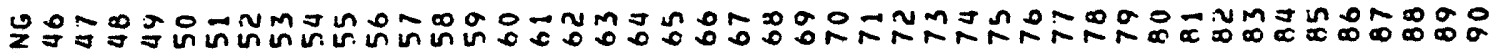
$\frac{2}{x}$

I N

G000-NW-000-ma

$\frac{2}{x}$

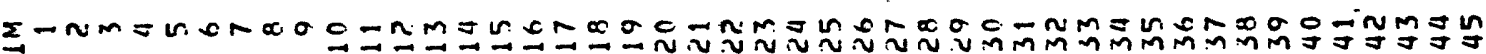
选

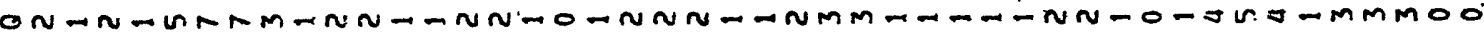
$\frac{1}{\alpha}$

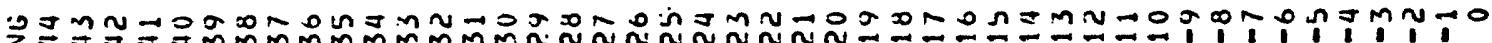

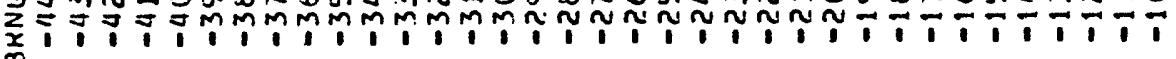

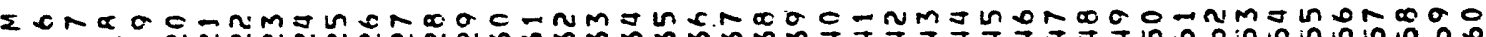

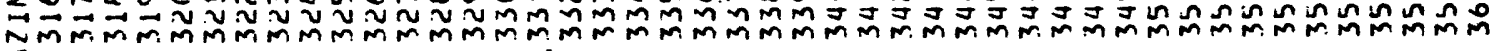

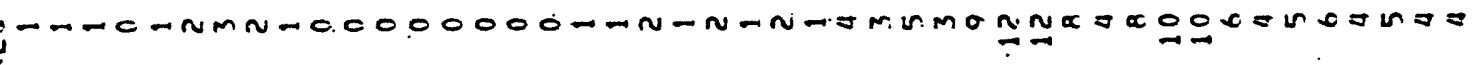
$\stackrel{\alpha}{4}$

פo

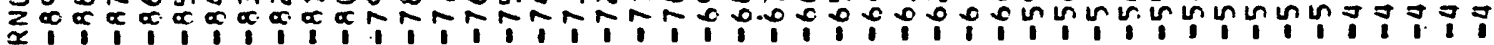

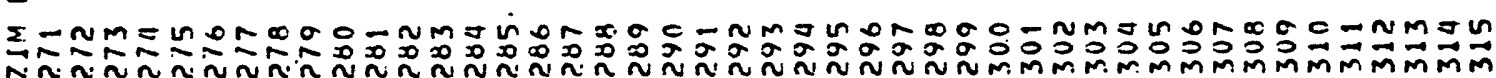

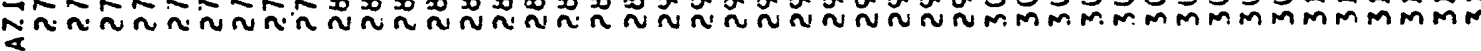




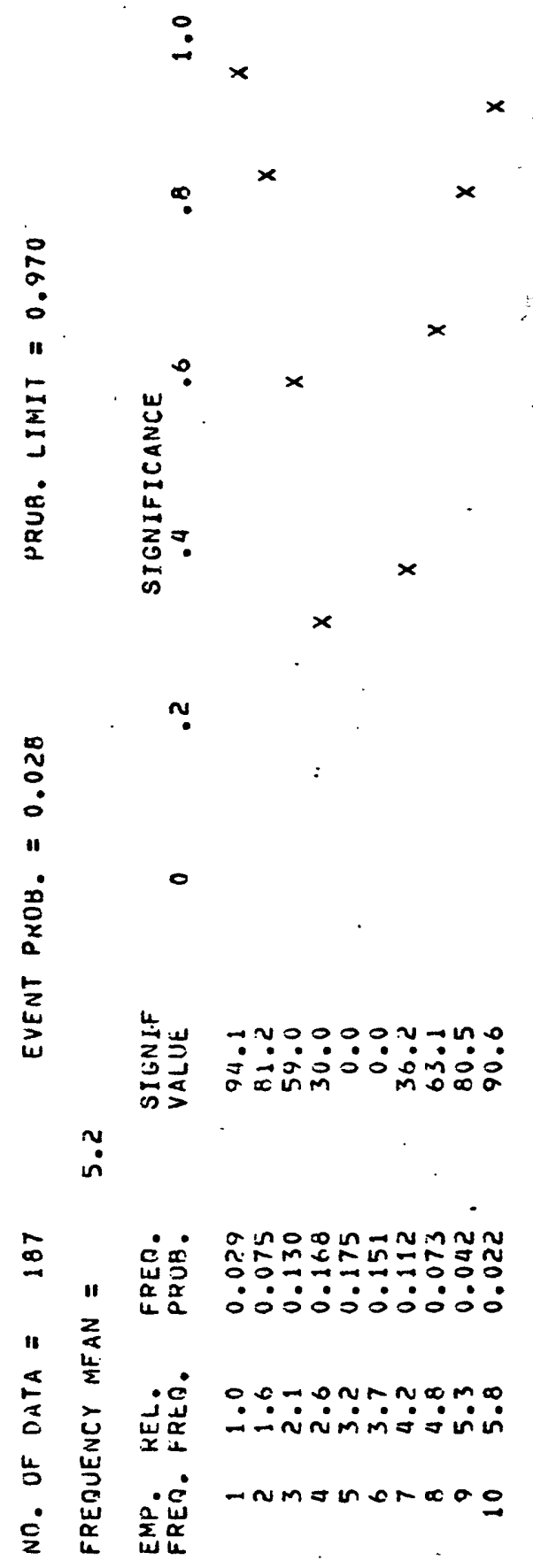




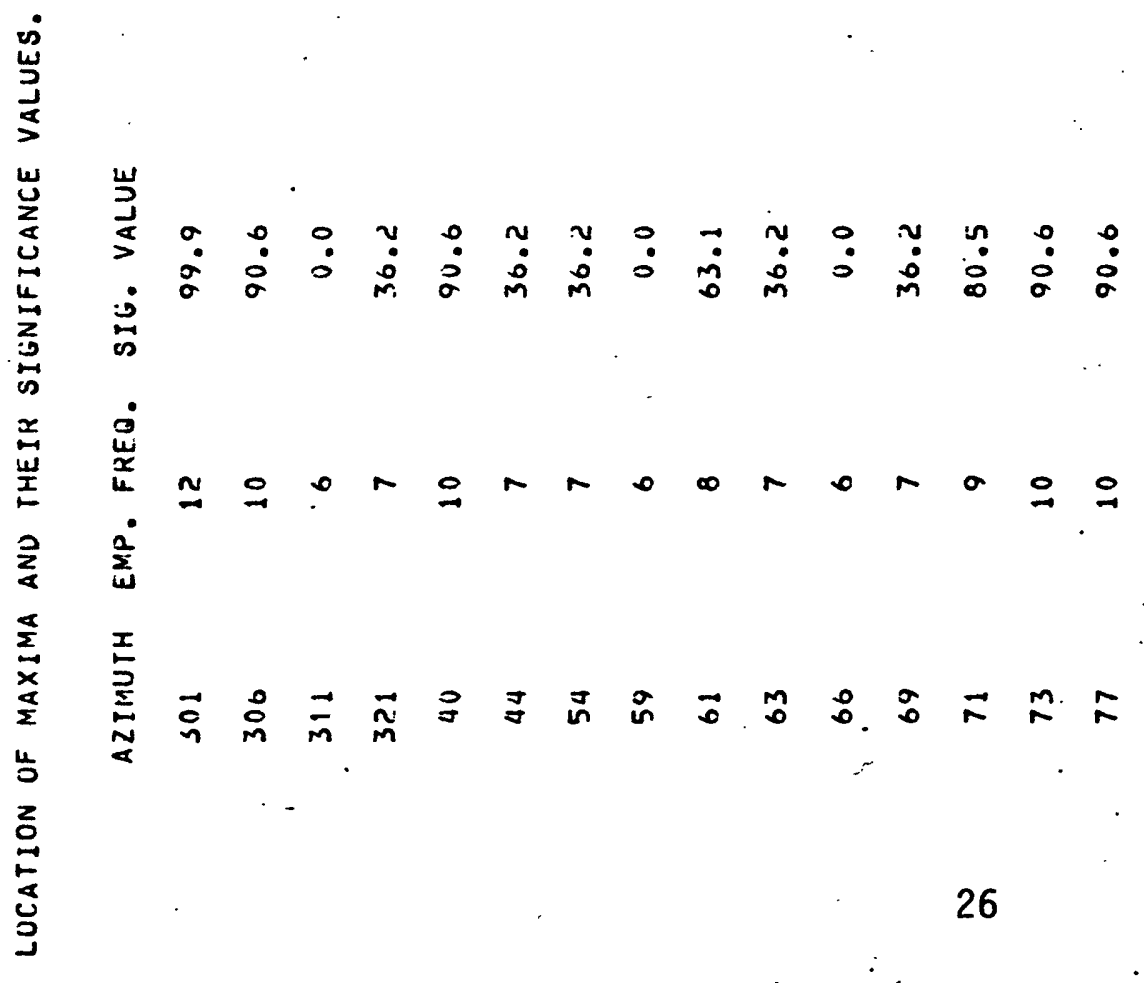




\author{
Appendix C \\ Computer Printout \\ Length-Weighted Strike-Frequency Analys is
}




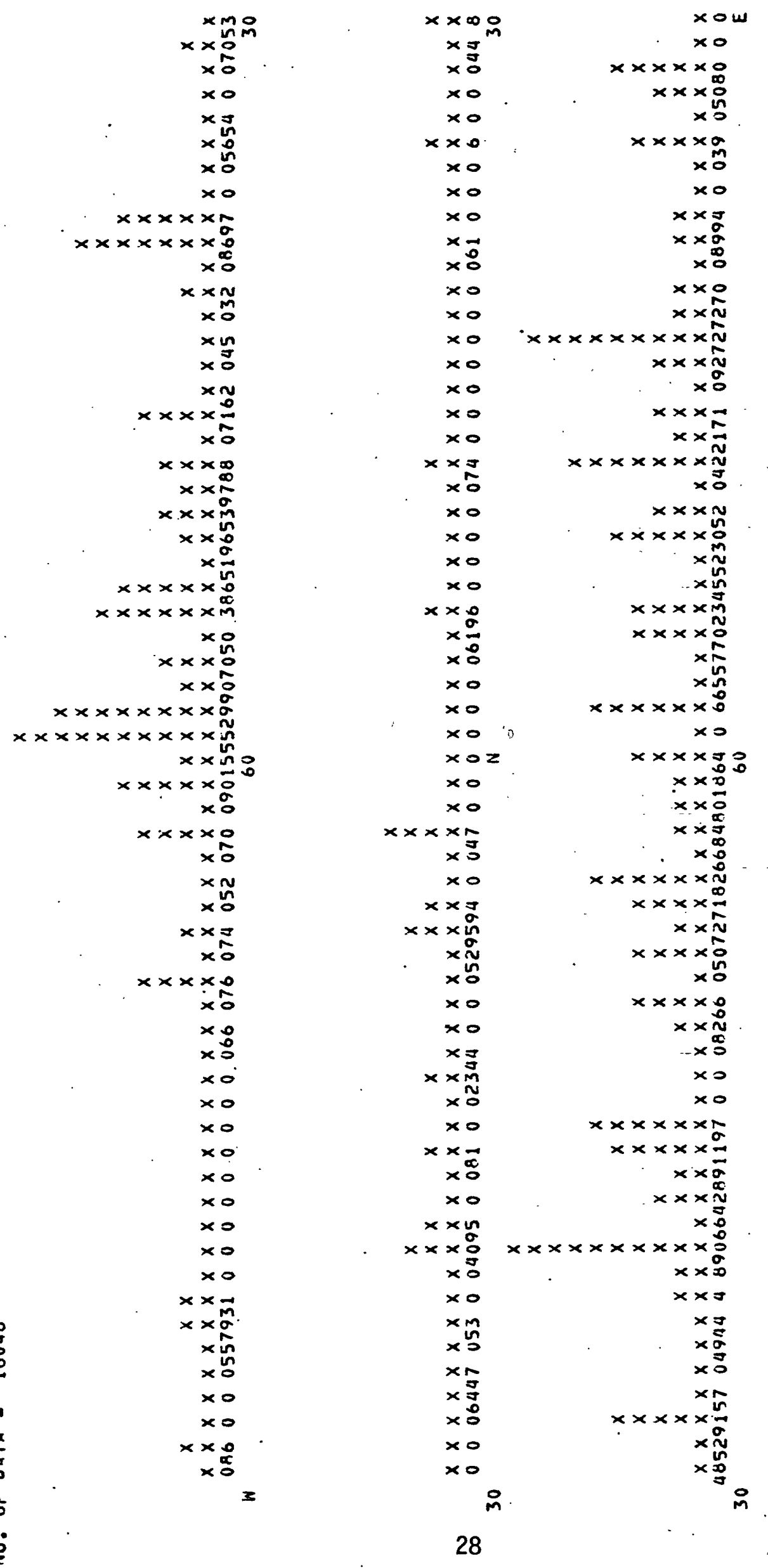




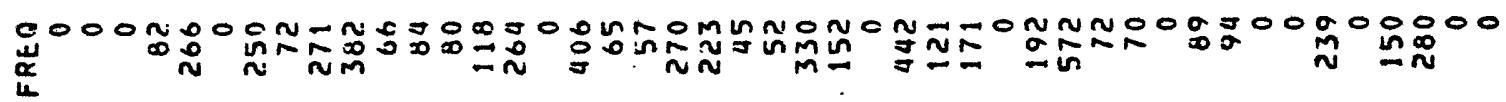

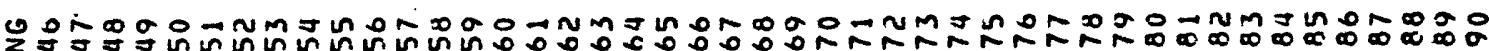
$\frac{z}{x}$

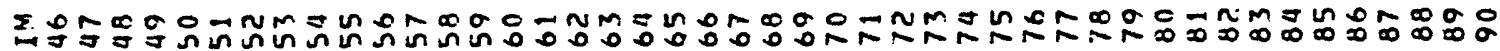

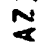

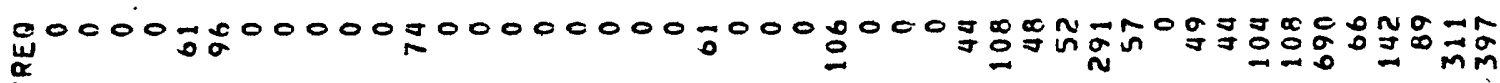
宸 $\frac{2}{10}$ $\sum_{N}-N m=$ I \&

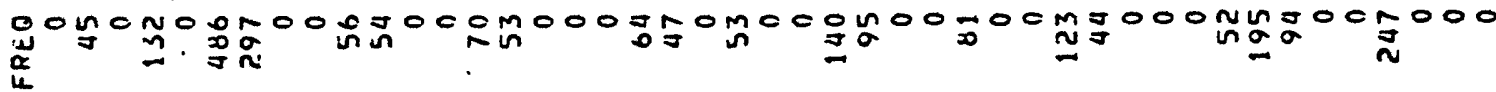

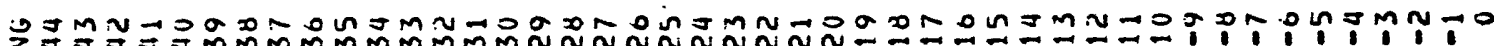

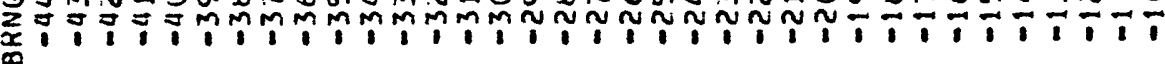

I0R

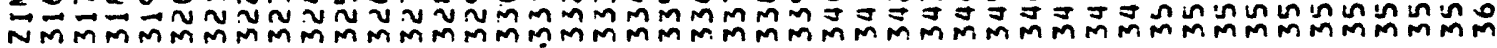

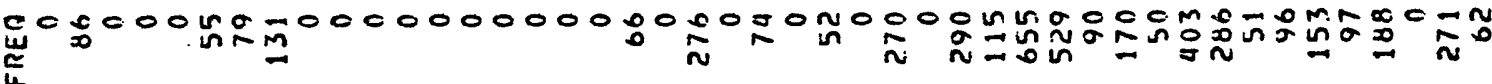
16

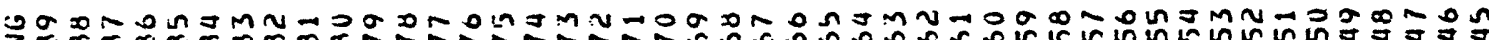

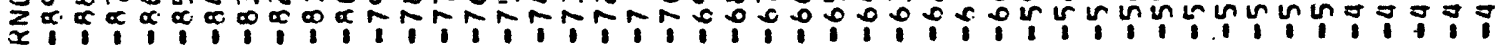

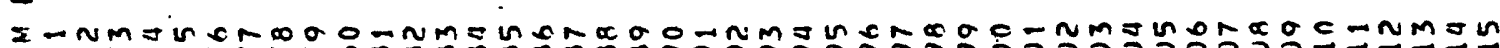

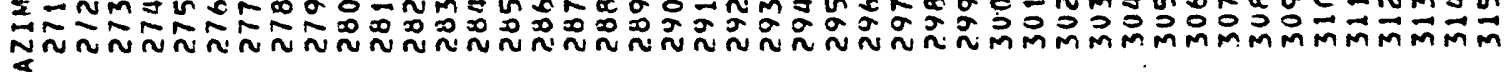




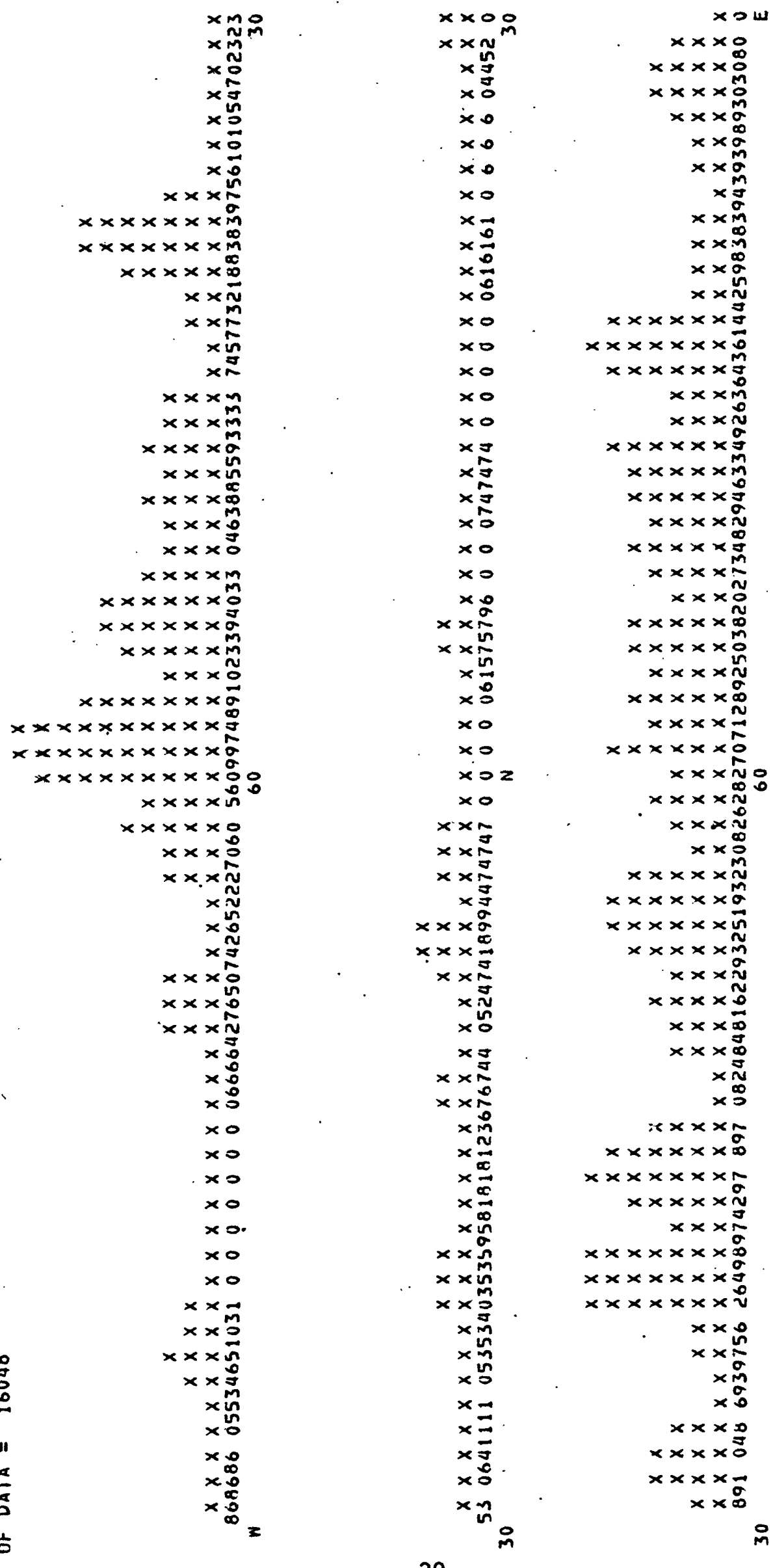




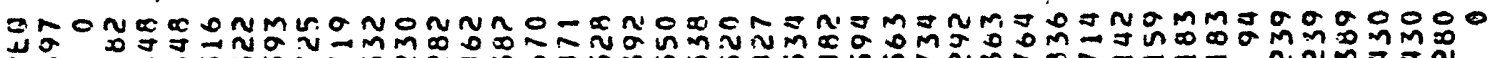

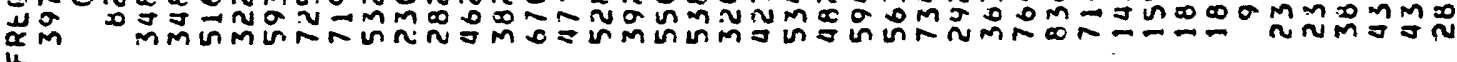

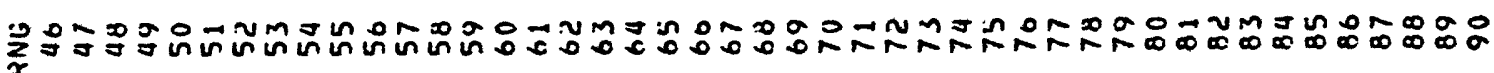
$\underset{x}{x}$

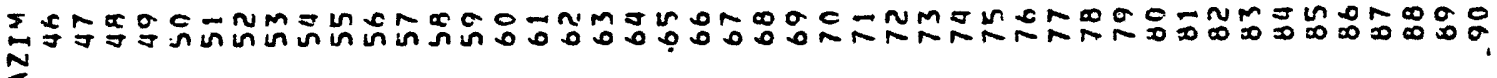

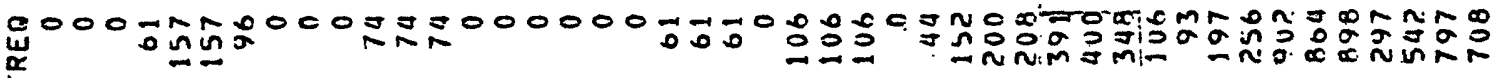
L 국ำ $\underset{x}{x}$

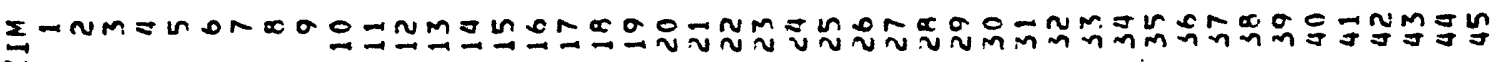
$\hat{a}$

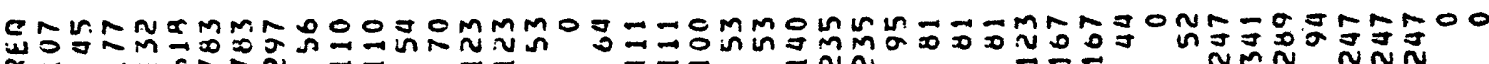
L

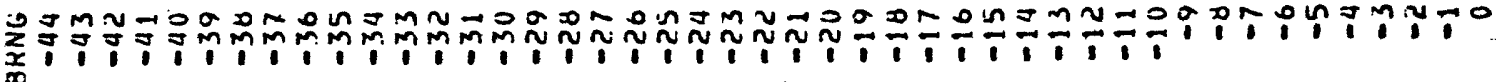

Ien 00 플

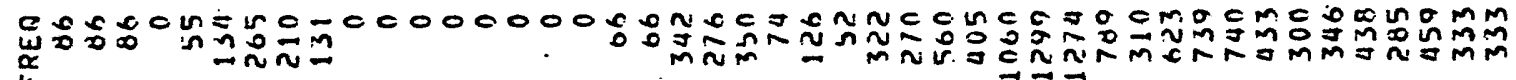

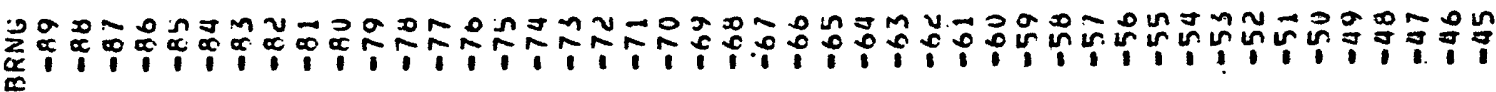

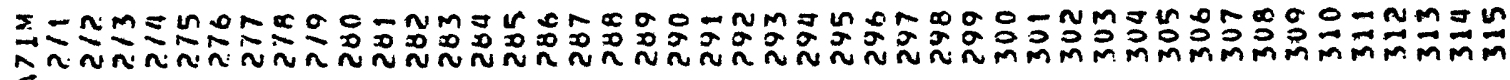




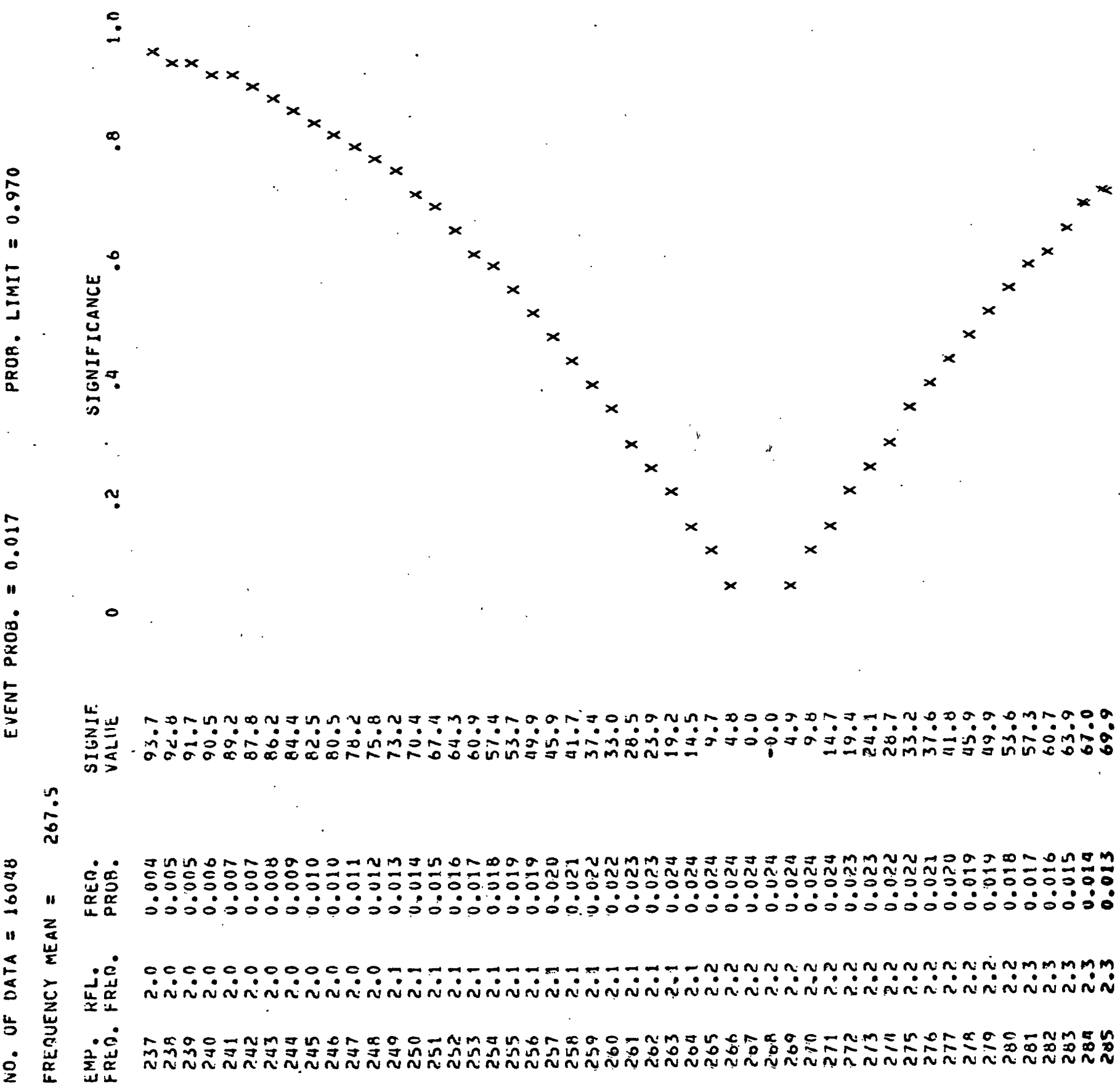




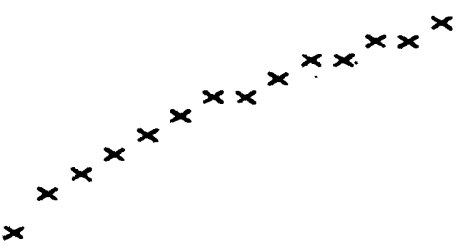

에

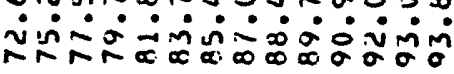

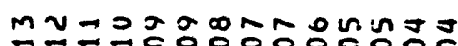

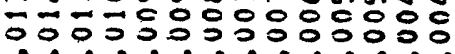
00505005000000

mmmmmmmmmmm $=0$ ininininininini

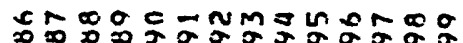

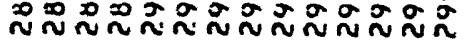




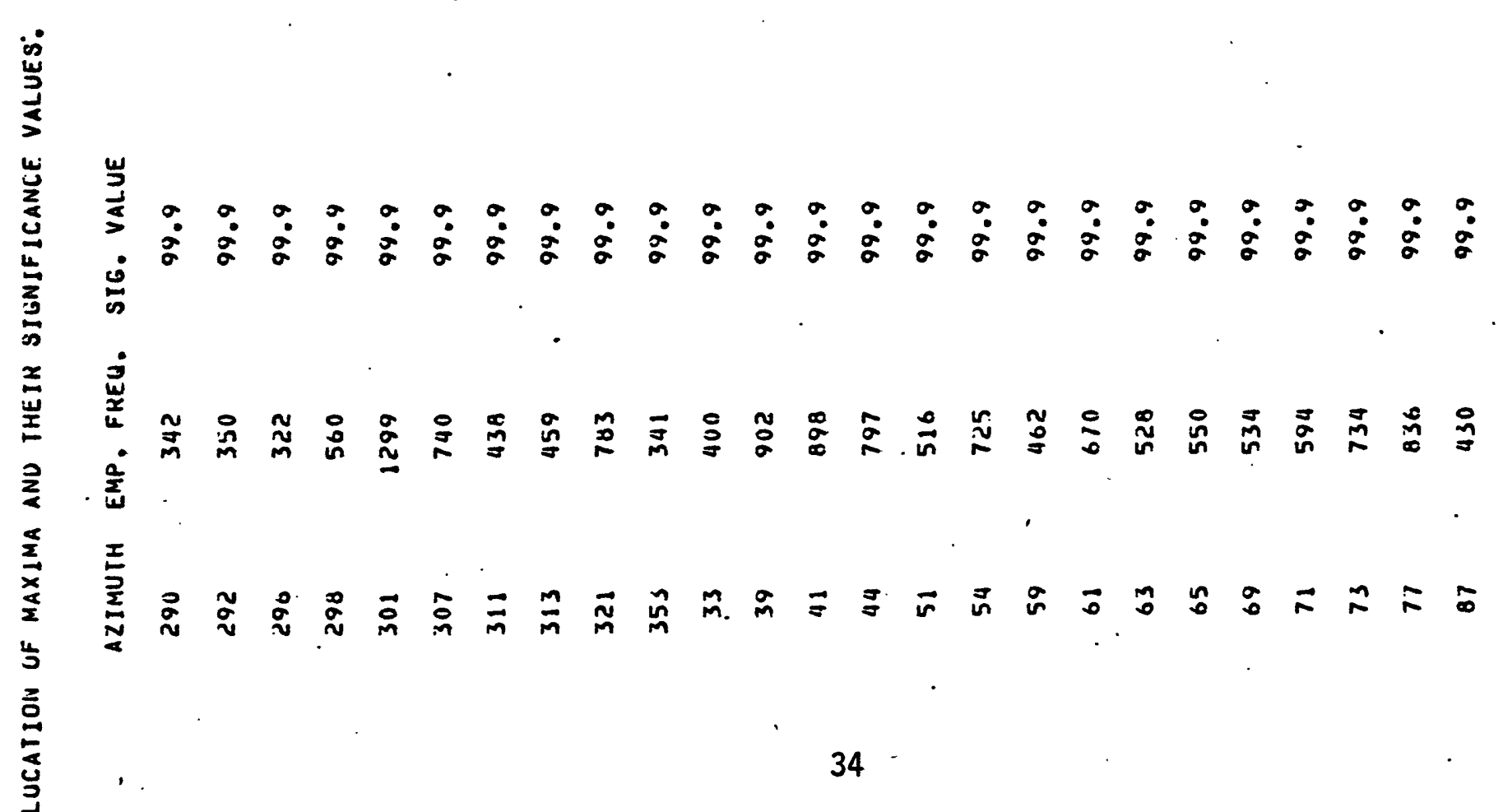

